\title{
Screening for mutations in a genetically heterogeneous disorder: DHPLC versus DNA sequence for mutation detection in multiple genes causing Charcot-Marie-Tooth neuropathy
}

\author{
Hiroshi Takashima, $M D, P h D^{1}$, Cornelius F. Boerkoel, $M D, P h D^{1}$, and James R. Lupski, MD, PhD ${ }^{1,2}$
}

\begin{abstract}
Purpose: To determine the efficacy of denaturing high-performance liquid chromatography (DHPLC) for mutation detection in genetically heterogeneous diseases using Charcot-Marie-Tooth neuropathy as a model. Methods: (1) Identification of the optimal conditions for mutation scanning by DHPLC using 50 known variants of PMP22, MPZ, GJB1 and EGR2. (2) Comparison of DHPLC with DNA sequencing for mutation detection in 168 patient DNA samples. Results: We established the optimal conditions for screening PMP22, MPZ, GJB1, and EGR2 for mutations. Under optimized conditions, DHPLC was as sensitive as DNA sequencing and detected two mutations that were not identified by automated DNA sequence. Conclusions: DHPLC increases the efficiency and sensitivity of mutation screening in genetically heterogeneous diseases. Genet Med 2001:3(5):335-342.
\end{abstract}

Key Words: mutation scanning, inherited neuropathy, genetic heterogeneity, direct sequencing, heteroduplex analysis

During the past decade, molecular genetic analyses of human disease phenotypes have revealed that different genes may be responsible for the same disorder in different families. In fact, genetic heterogeneity appears to be the rule rather than the exception for human diseases. Flagrant examples include sensorineural deafness (MIM\#220700, \#124900) $)^{1-3}$ retinitis pigmentosa (MIM\#268000, RetNet [http://www.sph.uth.tmc. edu/retnet/]), ${ }^{4-6}$ and peripheral neuropathy (MIM 118220, $118200),{ }^{7-10}$ wherein at least 49,28 , and 15 different loci have been described, respectively. Because of clinical as well as genetic heterogeneity, a precise molecular diagnosis is often needed to make a clinical diagnosis secure, enable genetic counseling of the patient and family, offer potential prenatal diagnosis, and provide prognostic information for the patient. Unfortunately, concomitant with the increase in the number of genes that must be screened for mutations, the labor and reagent costs for molecular genetic testing has increased significantly.

The gold standard for mutation detection has been direct sequence analysis. However, the cost and effort of DNA sequencing is often considerable, especially in genetically heterogeneous diseases. Although mutation scanning techniques such as heteroduplex analysis, single-strand conformation

From the ${ }^{1}$ Department of Molecular and Human Genetics, Baylor College of Medicine, and ${ }^{2}$ Department of Pediatrics, Texas Children's Hospital, Houston, Texas.

Drs. Takashima and Boerkoel contributed equally to this work.

James R. Lupski, MD, PhD, Department of Molecular and Human Genetics, Baylor College of Medicine, One Baylor Plaza, Room 604B, Houston, TX 77030.

Received: May 10, 2001.

Accepted: June 28, 2001. polymorphism (SSCP), and denaturing gradient gel electrophoresis (DGGE) are more economical, the sensitivity of these techniques is usually $<75 \%$, a sensitivity suboptimal for clinical service. ${ }^{11,12}$ High throughput, cost-effective, and sensitive mutation scanning methods are desperately needed if the power of molecular genetics is to be realized in clinical practice; particularly with respect to conditions manifesting genetic heterogeneity.

Based on recent reports, denaturing high-performance liquid chromatography (DHPLC) appears to be an economical and highly sensitive method for mutation detection. ${ }^{11,13-19}$ This technique detects heteroduplexes containing a mutation or polymorphism by reduced column retention of heteroduplexes compared to the respective homoduplexes under partially denaturing conditions. ${ }^{13,14}$ Compared to sequencing, the reported sensitivity of DHPLC ranges from $92.5 \%$ to $100 \%,{ }^{11,14-19}$ and the reagent costs are approximately $10 \%$ to $20 \%$ of the cost for sequencing. Given this economy, sensitivity, and simplicity, we considered DHPLC to be a potentially ideal initial mutation screening method for genetically heterogeneous diseases. DNA sequencing could then be limited to those samples and genes with DHPLC-derived evidence for a DNA alteration.

In order to test the application of DHPLC to a genetically heterogeneous disease, we applied DHPLC to mutation screening in Charcot-Marie-Tooth neuropathy (CMT [MIM118200]), one of the most common inherited neurological diseases. ${ }^{7,8}$ At least 15 genetic loci and 9 genes have been associated with CMT and related neuropathies, including congenital hypomyelinating neuropathy (CHN [MIM605253]), Dejerine-Sottas neuropathy (DSN [MIM 145900]), and hered- 
itary neuropathy with liability to pressure palsy (HNPP [MIM 162500]). ${ }^{7-10}$ Point mutations in one of four genes (PMP22, $M P Z, G J B 1$, and EGR2) account for the majority of inherited peripheral neuropathy patients who do not have a DNA rearrangement (the CMTA duplication or the HNPP deletion) as a cause of their disease. Because mutation of most of these genes can give rise to a spectrum of peripheral neuropathies that can sometimes be difficult to distinguish from acquired neuropathies, mutation detection occupies a very important position in the diagnosis of CMT and related neuropathies and the management of patients.

In addition to improving the efficiency of mutation screening for CMT, we hypothesized that detection of a heteroduplex by DHPLC might improve the mutation detection rate for sequencing. Although sequencing has been the gold standard for mutation detection, data from sequence chromatograms are not always ideal and sequence analysis programs occasionally fail to detect heterozygous mutations. The supporting data of a heteroduplex peak in a DHPLC elution profile can be very helpful for focusing further sequencing efforts and scrutiny of the sequence chromatograms. If this hypothesis were true, we reasoned that we could identify new mutations in the DNA samples from patients previously screened by direct sequencing. To this end, we assembled a cohort of $168 \mathrm{CMT}$ patient DNA samples that had tested negative for mutations by direct DNA sequencing and screened the DNA samples for PMP22, $M P Z, G J B 1$, and EGR2 mutations by DHPLC. Under the optimized DHPLC conditions, we report for screening these four genes, we detected two GJB1 mutations missed by automated DNA sequence analysis.

\section{MATERIALS AND METHODS}

\section{Human subjects}

We analyzed 218 patients with CMT; 50 patients with a previously identified mutation of a CMT-associated gene and 168 patients who had tested negative for mutations by direct sequencing. Excepting a false-negative test result, patients without a mutation in one of the known CMT-associated genes usually have a mutation in another gene that has not yet been associated with CMT; this is exemplified by our recent identification of mutations in the Periaxin gene $(P R X)$ as a cause of severe CMT. ${ }^{9}$ All patients referred for this study by their primary physician or neurologist gave informed consent approved by the Institutional Review Board of Baylor College of Medicine. We isolated DNA from the peripheral blood of each patient and established lymphoblastoid cell lines.

\section{Mutation screening by direct sequencing}

Primers for PCR amplification of exons and intronic splice junctions were designed using the Primer v3 program ( $h t t p: / /$ www-genome.wi.mit.edu/cgi-bin/primer/primer3_www.cgi) (Table 1). All forward primers had a $-21 \mathrm{M} 13$ primer tail (TGTAAAACGACGGCCAGT), and all reverse primers had an M13 reverse tail (CAGGAAACAGCTATGACC). Using $50 \mathrm{ng}$ of patient genomic DNA, the appropriate primers and Qiagen Hot-
Table 1

Primer pairs used for amplifying the $M P Z, P M P 22$, and GJB1 coding regions

\begin{tabular}{|c|c|c|}
\hline Gene & $\begin{array}{l}\text { Primer } \\
\text { name }\end{array}$ & Primer pairs \\
\hline \multicolumn{3}{|l|}{ MPZ } \\
\hline & Exon $1 \mathrm{~F}$ & ССАССТСТСАACTGCACATG \\
\hline & $\mathrm{R}$ & ATTGCTGAGAGACACCTGAGTCC \\
\hline & Exon $2 \mathrm{~F}$ & TCCTCTGTATCCCTTACTGG \\
\hline & $\mathrm{R}$ & TTTGAAGCACTTTCTGTTATCC \\
\hline & Exon $3 \mathrm{~F}$ & GGAGCTAAGCTTTGACAGCTGTG \\
\hline & $\mathrm{R}$ & АТССССТСССАAАСТGСТTC \\
\hline & Exon $4 \mathrm{~F}$ & CGGACTAGGAACCACAGATAC \\
\hline & $\mathrm{R}$ & TCCGCCCAGATGGGGGATAG \\
\hline & Exon $5 \mathrm{~F}$ & TGTGTCCGCGGTGCAAGGGGTTC \\
\hline & $\mathrm{R}$ & CTCCCAGGGTTCTCCTTCCCA \\
\hline & Exon $6 \mathrm{~F}$ & AAGCCCCAGTCGCTCGGTGA \\
\hline & $\mathrm{R}$ & CTTTGGGCCTTTGGCGGACTC \\
\hline
\end{tabular}

PMP22

$\begin{aligned} \text { Exon 2 F } & \text { CTAGTGCGCGGGACCCTC } \\ \mathrm{R} & \text { CTGAACCAGCAGGAGCACGGGCTG } \\ \text { Exon 3 F } & \text { CATGCAGGGGTGGGCGGTGTG } \\ \mathrm{R} & \text { GGGCTGAGAAACGTGTTACAG } \\ \text { Exon 4 F } & \text { TGGCCCTTCAGGCCCTGCACCT } \\ \mathrm{R} & \text { CCCACACATACAAGCACCCACCCTCA } \\ \text { Exon 5 F } & \text { TTCCTACCCAGCAATTGTCAGC } \\ \mathrm{R} & \text { CTTCCTCCCTTCCCTATGTACG }\end{aligned}$

GJB1

$\begin{aligned} \text { Exon 2a F } & \text { CCAGCTTTCTGACAGCTTGCT } \\ \mathrm{R} & \text { CTCAAACAACAGCCGGAACAC } \\ \text { Exon 2b F } & \text { GCACAAGGTCCACATCTCAGG } \\ \mathrm{R} & \text { AGGGCAGGGTCGGGGATGGATG }\end{aligned}$

EGR2

$\begin{aligned} \text { Exon 1 F } & \text { CAGCAACTTGTTTGCTACTTTTATTTCTG } \\ \mathrm{R} & \text { GTCTTCAAAGCCAGTGCAGTCAGC } \\ \text { Exon 2a F } & \text { AATTTCCCCACCTTTTGGAC } \\ \mathrm{R} & \text { GCAGAAGGGTCCTGGTAGAG } \\ \text { Exon 2b F } & \text { AGCTTCAACCACAGCCTCAT } \\ \mathrm{R} & \text { CTGCTGCTGAGCTGCTACC } \\ \text { Exon 2c F } & \text { CAGACTATCCTGGATTCTTTCCAT } \\ \mathrm{R} & \text { GCTTATGCCCAGTGTGGATT } \\ \text { Exon 2d F } & \text { ATTCTGAGGCCTCGCAAGTA } \\ \mathrm{R} & \text { GTTTGTTGTGCAGCTCCAGTG }\end{aligned}$

StarTaq, each region was amplified as follows: 15 minutes at $95^{\circ} \mathrm{C}$, 40 cycles of amplification $\left(95^{\circ} \mathrm{C}\right.$ for 30 seconds, $65^{\circ} \mathrm{C}$ for $30 \mathrm{sec}-$ 
Table 2

List of 50 patients with variants in CMT causative genes

\begin{tabular}{|c|c|c|c|c|c|c|c|}
\hline \multirow[b]{2}{*}{ Gene } & \multirow[b]{2}{*}{ Patients } & \multicolumn{2}{|c|}{ Variants } & \multirow[b]{2}{*}{ Gene } & \multirow[b]{2}{*}{ Patients } & \multicolumn{2}{|r|}{ Variants } \\
\hline & & Nucleotide & Amino acid & & & Nucleotide & Amino acid \\
\hline PMP22 & & & & $M P Z$ & & & \\
\hline \multirow[t]{3}{*}{ Exon 3} & BAB666 & $82 \mathrm{~T}>\mathrm{C}$ & Trp28Arg & Exon 5 & BAB136 & $600 \mathrm{G}>\mathrm{A}$ & Gly200Gly \\
\hline & BAB667 & $82 \mathrm{~T}>\mathrm{C}$ & Trp28Arg & & BAB808 & $600 \mathrm{G}>\mathrm{A}$ & Gly200Gly \\
\hline & & & & & BAB987 & $556 \mathrm{G}>\mathrm{A}$ & Glu186X \\
\hline \multicolumn{8}{|l|}{ Exon 4} \\
\hline & BAB686 & $236 \mathrm{C}>\mathrm{G}$ & Ser79Cys & Exon 6 & & & \\
\hline & BAB687 & $236 \mathrm{C}>\mathrm{G}$ & Ser79Cys & & BAB115 & $684 \mathrm{C}>\mathrm{T}$ & Ser228Ser \\
\hline & BAB1348 & 281delG & Gly94fsX110 & & BAB1161 & $684 \mathrm{C}>\mathrm{T}$ & Ser228Ser \\
\hline \multirow[t]{6}{*}{ Exon 5} & & & & GJB1 & & & \\
\hline & BAB117 & $353 \mathrm{C}>\mathrm{T}$ & Thr118Met & Exon 2 & BAB123 & $43 \mathrm{C}>\mathrm{T}$ & Arg15Trp \\
\hline & BAB788 & $353 \mathrm{C}>\mathrm{T}$ & Thr118Met & & BAB545 & 43delC & $\operatorname{Arg} 15 \mathrm{fs}$ \\
\hline & BAB1147 & $418 \mathrm{~T}>\mathrm{A}$ & Trp140Arg & & BAB1007 & $285 \mathrm{G}>\mathrm{A}$ & Val95Met \\
\hline & BAB1162 & $353 \mathrm{C}>\mathrm{T}$ & Thr118Met & & PN-56.1 & 424delC & Phe141fsX195 \\
\hline & & & & & & G713A & Arg238His \\
\hline$M P Z$ & & & & & PN-56.2 & G713A & Arg238His \\
\hline \multirow[t]{2}{*}{ Exon 2} & $\mathrm{PN}-24$ & $233 \mathrm{C}>\mathrm{T}$ & Ser78Leu & & PN-135.1 & $\mathrm{C} 842 \mathrm{~A}$ & Ser281X \\
\hline & PN-559 & 225delG & Gly75fs & & PN-135.2 & $\mathrm{C} 842 \mathrm{~A}$ & Ser281X \\
\hline \multirow[t]{15}{*}{ Exon 3} & & & & EGR2 & & & \\
\hline & BAB238 & $245 \mathrm{~A}>\mathrm{G}$ & Tyr82Cys & Exon 2 & BAB615 & $1225 \mathrm{C}>\mathrm{T}$ & Arg409Trp \\
\hline & BAB511 & $292 \mathrm{C}>\mathrm{T}$ & Arg98Ser & & BAB619 & $3333 \mathrm{~T}>\mathrm{A}$ & $3^{\prime} \mathrm{UTR}$ \\
\hline & BAB731 & $409 \mathrm{G}>\mathrm{A}$ & Gly137Ser & & BAB905 & $803 \mathrm{~T}>\mathrm{A}$ & Ile268Asn homozygote \\
\hline & BAB921 & $409 \mathrm{G}>\mathrm{A}$ & Gly137Ser & & & & \\
\hline & BAB923 & $409 \mathrm{G}>\mathrm{A}$ & Gly137Ser & & BAB906 & $803 \mathrm{~T}>\mathrm{A}$ & Ile268Asn homozygote \\
\hline & BAB1022 & $292 \mathrm{C}>\mathrm{T}$ & Arg98Cys & & & & \\
\hline & BAB1047 & 306delA & Glu102fs homozygote & & BAB907 & $803 \mathrm{~T}>\mathrm{A}$ & Ile268Asn heterozygote \\
\hline & BAB1050 & 306delA & Glu102fs heterozygote & & ВАВ908 & $803 \mathrm{~T}>\mathrm{A}$ & Ile268Asn heterozygote \\
\hline & BAB 1100 & $341 \mathrm{~T}>\mathrm{C}$ & Ile114Thr & & BAB1083 & ${ }^{\star} 1075 \mathrm{C}>\mathrm{T}$ & Arg359Trp \\
\hline & & $346 \mathrm{~A}>\mathrm{C}$ & Asn116His & & BAB1085 & $1146 \mathrm{~T}>\mathrm{G}$ & Ser382Arg \\
\hline & & $382 \mathrm{G}>\mathrm{A}$ & Asp128Asn & & & $1147 \mathrm{G}>\mathrm{T}$ & Asp383Tyr \\
\hline & BAB1107 & $292 \mathrm{C}>\mathrm{T}$ & Arg98Cys & & BAB1091 & ${ }^{\star} 1075 \mathrm{C}>\mathrm{T}$ & Arg359Trp \\
\hline & BAB1370 & $367 \mathrm{G}>\mathrm{T}$ & Gly123Cys & & BAB1158 & ${ }^{\star} 1086 \mathrm{~A}>\mathrm{C}$ & Arg362Arg \\
\hline & & & & & BAB1223 & $1352 \mathrm{G}>\mathrm{T}$ & Gly451Val \\
\hline \multirow[t]{6}{*}{ Exon 4} & & & & & & ${ }^{\star} 1086 \mathrm{~A}>\mathrm{C}$ & Arg362Arg \\
\hline & BAB1040 & $522-525$ & Leu174fs & & BAB1345 & $1352 \mathrm{G}>\mathrm{T}$ & Gly451Val \\
\hline & & delGCTT & & & & ${ }^{\star} 1086 \mathrm{~A}>\mathrm{C}$ & $\operatorname{Arg} 362 \operatorname{Arg}$ \\
\hline & PN-78 & $462 \mathrm{C}>\mathrm{A}$ & Trp154X & & & & \\
\hline & PN-227 & $487 \mathrm{G}>\mathrm{A}$ & Gly163Arg & & & & \\
\hline & $\mathrm{PN}-35$ & $543 \mathrm{C}>\mathrm{G}$ & Trp181X & & & & \\
\hline
\end{tabular}

Asterisks identify mutations included in both EGR2 2c and 2d amplicons.

onds, $72^{\circ} \mathrm{C}$ for 1 minute), and 7 minutes at $72^{\circ} \mathrm{C}$. Amplification of EGR2 amplicons 2a, 2b, and 2d required the addition of Qiagen Q buffer to $20 \%$. PCR products amplified from the genomic DNA of patients, relatives, and control chromosomes were purified using the Qiagen 96-PCR purification kit (Qiagen), and the products were sequenced with dye-primer chemistry (Applied Biosystems) 
Table 3

Sensitivity of mutation detection at various DHPLC column temperatures for coding amplicons of PMP22, MPZ, GJB1, and EGR2

\begin{tabular}{|c|c|c|c|c|c|c|c|c|c|c|c|c|}
\hline & \multirow[b]{2}{*}{$\begin{array}{l}\text { Amplicon } \\
\text { size (bp) }\end{array}$} & \multicolumn{2}{|c|}{$\begin{array}{l}\text { Predicted optimal column temperatures } \\
\qquad\left({ }^{\circ} \mathrm{C}\right)\end{array}$} & \multicolumn{8}{|c|}{$\begin{array}{l}\text { No. of mutations detected at a DHPLC column temperature } \\
\qquad\left({ }^{\circ} \mathrm{C}\right)\end{array}$} & \multirow[b]{2}{*}{$\begin{array}{l}\text { Total no. of } \\
\text { mutations }\end{array}$} \\
\hline & & $\begin{array}{l}\text { WAVE } \\
\text { MAKER }{ }^{\circledR}\end{array}$ & $\begin{array}{l}\text { Stanford DHPLC } \\
\text { Melt program }\end{array}$ & $59^{\circ}$ & $60^{\circ}$ & $61^{\circ}$ & $62^{\circ}$ & $63^{\circ}$ & $64^{\circ}$ & $65^{\circ}$ & $66^{\circ}$ & \\
\hline \multicolumn{13}{|l|}{ PMP22 } \\
\hline $\operatorname{exon} 2^{a}$ & 312 & $65 \& 67$ & $59 \& 64$ & & & & & & & & & \\
\hline exon 3 & 327 & 61 & 61 & 0 & 1 & 2 & 0 & 0 & & & & 2 \\
\hline exon 4 & 419 & 61 & 61 & & 3 & 3 & 3 & 0 & 0 & & & 3 \\
\hline exon 5 & 348 & 64 & 62 & & & 0 & 1 & 1 & 4 & 0 & & 4 \\
\hline \multicolumn{13}{|l|}{$M P Z$} \\
\hline $\operatorname{exon} 1^{a}$ & 328 & 64 & 62 & & & & & & & & & \\
\hline exon 2 & 310 & 64 & 62 & & 2 & 2 & 2 & 2 & 0 & & & 2 \\
\hline exon 3 & 366 & 61 & 60 & 2 & 10 & 2 & 0 & 0 & & & & 10 \\
\hline exon 4 & 290 & 64 & 62 & & 3 & 4 & 4 & 4 & 3 & & & 4 \\
\hline exon 5 & 204 & 64 & 62 & & 2 & 2 & 3 & 3 & 3 & & & 3 \\
\hline exon 6 & 241 & 64 & 62 & & & 0 & 2 & 2 & 2 & 2 & & 2 \\
\hline \multicolumn{13}{|l|}{ GJB1 } \\
\hline exon 2-a & 531 & 62 & 61 & & & 1 & 3 & 2 & 0 & 0 & & 3 \\
\hline exon 2-b & 561 & 64 & 63 & & & & 1 & 4 & 4 & 1 & 0 & 4 \\
\hline \multicolumn{13}{|l|}{ EGR2 } \\
\hline $\operatorname{exon} 1^{a}$ & 523 & 62 & $58 \& 63$ & & & & & & & & & \\
\hline exon $2-\mathrm{a}^{a}$ & 572 & 61 & 62 & & & & & & & & & \\
\hline exon 2-b & 560 & 63 & 62 & & 0 & 0 & 3 & 0 & 0 & 0 & & 3 \\
\hline exon 2-c & 471 & $64 \& 67$ & $59 \& 64$ & & 7 & 7 & 5 & 3 & 2 & 0 & & 7 \\
\hline exon 2-d & 530 & 65 & 63 & & & & 0 & 2 & 7 & 4 & 0 & 7 \\
\hline
\end{tabular}

Empirically determined optimal DHPLC column temperatures are in bold.

${ }^{a}$ Known sequence variants of amplicons PMP22 ex2, MPZ ex1, and EGR2 ex1 and ex2a were not available for this study.

using an ABI377 automated sequencer (Applied Biosystems). We aligned resulting sequences and evaluated mutations with the Sequencher sequence alignment program (ACGT Codes). We numbered each cDNA sequence beginning with the adenine of the presumed initiating methionine and described mutations according to den Dunnen and Antonarakis. ${ }^{20}$

\section{Optimization of conditions for MPZ, PMP22, GJB1, and EGR2 mutation detection using DHPLC}

Using the Transgenomic WAVE® DNA-fragment analysis system (Omaha, NE), we optimized DHPLC analysis using 50 DNA samples from patients with known variants (Table 2). PCR amplification was performed using the primers and conditions described above. These amplicons span the entire coding region of each gene (PMP22, 4 exons; $M P Z, 6$ exons; GJB1, 1 large exon split into 2 amplicons; and EGR2, 2 exons split into 5 amplicons). In order to form heteroduplexes, for DHPLC analysis the PCR products were slowly cooled from $95^{\circ} \mathrm{C}$ to $25^{\circ} \mathrm{C}$ over 45 minutes. For detection of GJB1 mutations, an X-linked disease, the hetero- duplexes were formed after combining the PCR products from the patient with those from a normal control. We determined optimal DHPLC conditions empirically by systematically testing changes in the column temperature and acetonitrile gradient. We chose the initial column temperatures and acetonitrile gradient using the WAVEMAKER software v4.0 (Transgenomic, Inc.) and the Stanford DHPLC Melt program (www.insertions.stanford.edu/melt .htm). ${ }^{14}$

\section{Comparison of DHPLC versus direct sequencing}

To compare DHPLC and sequencing, we applied DHPLC to 168 CMT patient samples in which DNA sequence analysis was negative for PMP22, MPZ, GJB1, and EGR2 mutations. We mixed the PCR products from two patients in order to detect homozygous mutations. In those amplicons for which we observed a heteroduplex by DHPLC, we checked the archived sequence chromatograms for mutations by reading each base directly and confirmed the mutation by restriction endonuclease digestion. 
a MPZ exon 2
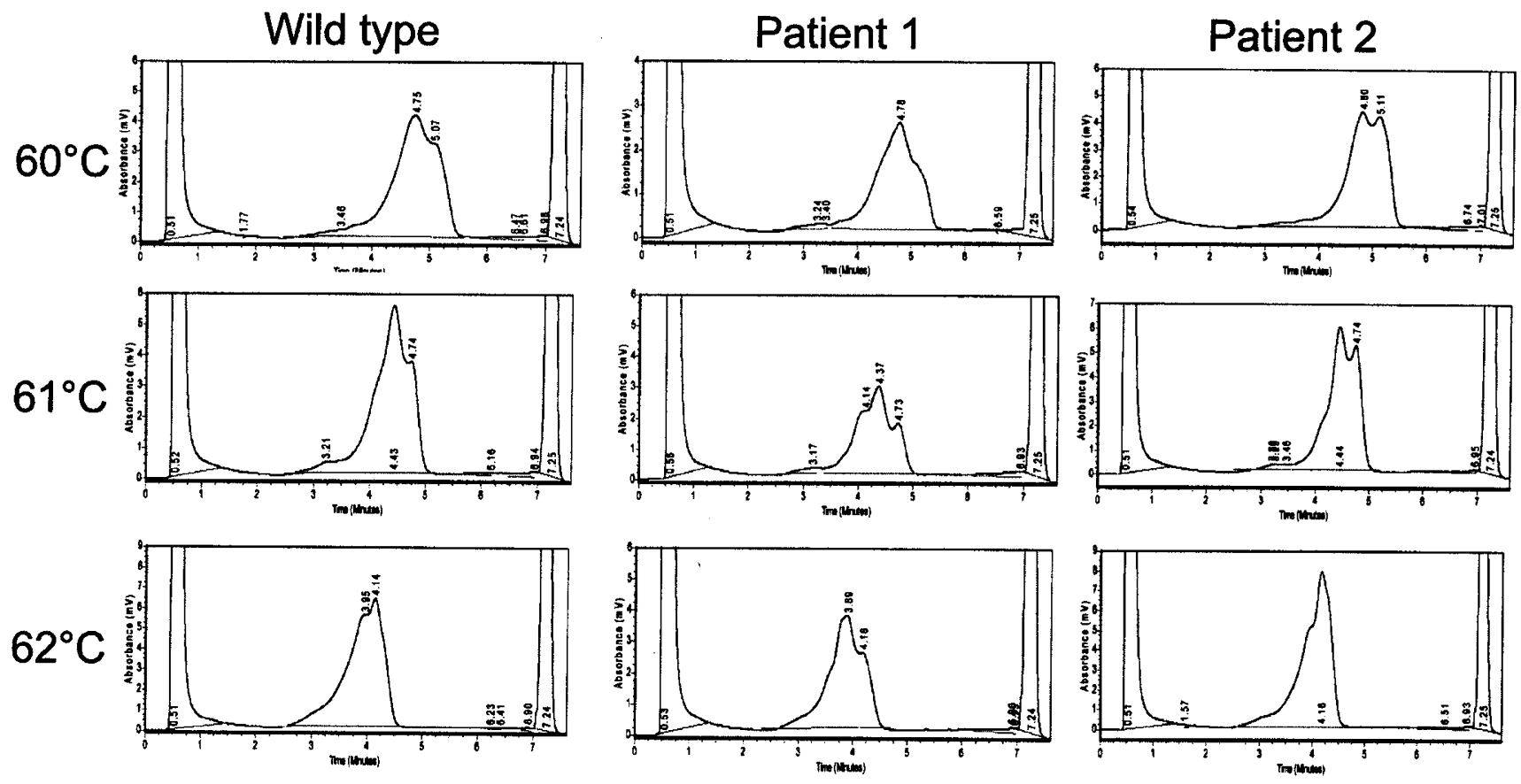

\section{b EGR2 exon $2 \mathrm{c}-63^{\circ} \mathrm{C}$}
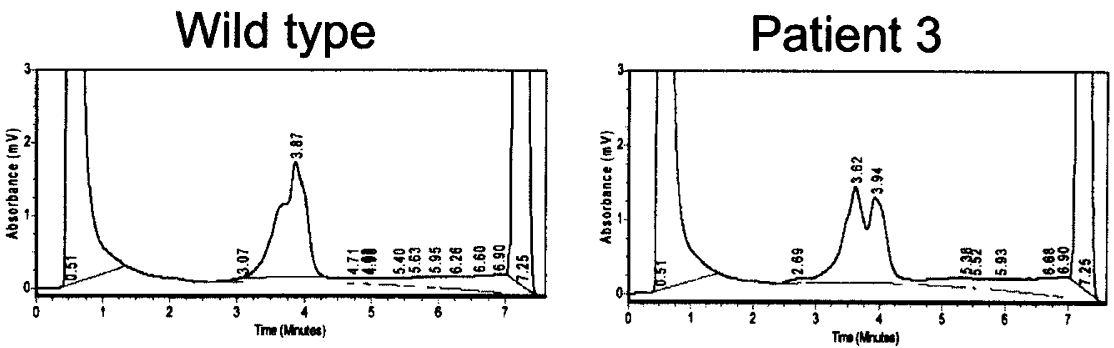

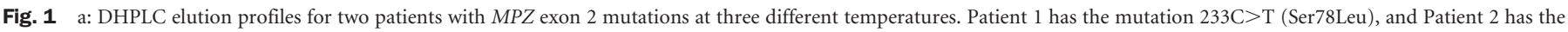
mutation 225delG (Gly75fs). b: DHPLC elution profile at $63^{\circ} \mathrm{C}$ for an EGR2 mutation $803 \mathrm{~T}>\mathrm{A}$ (Ile268Asn).

\section{RESULTS}

\section{Optimal conditions for MPZ, PMP22, GJB1, and EGR2 mutation detection using DHPLC}

To determine the best conditions for detection of mutations in CMT associated genes, we performed DHPLC analysis in 50 patients with known sequence alterations of PMP22, MPZ, GJB1, and EGR2. The temperature-dependent sensitivity of detecting mutations in each amplicon is shown in Table 3. We detected all heterozygous mutations, but as expected, did not detect homozygous mutations unless DNA samples were mixed with control DNA or another patient sample to form heteroduplexes. All mutations within $M P Z$ ex2, ex4, ex5, ex6, and PMP22 ex4 were detected at several different column temperatures. Some of these selected column temperatures did not match the best temperature predicted from the theoretical melting curve for each amplicon. In general, the WAVEMAKER 4.0 program predicted a column temperature $1-2^{\circ} \mathrm{C}$ higher than our empirically determined optimal column temperatures, whereas the Stanford DHPLC Melt program predicted our empirically determined column temperatures with at least 75\% accuracy. All mutations within MPZ ex3, PMP22 ex3, and ex5, and EGR2 amplicons $2 \mathrm{~b}$ and $2 \mathrm{~d}$ at only one column temperature. Sensitive screening of these amplicons requires very stringent conditions, because each mutation was detected only at the optimal column temperature. Therefore, based on this study, screening of each amplicon at more than one column temperature may be unnecessary, although the Tm and melting curve predicted by the Transgenomic WAVEMAKER program might suggest otherwise. 


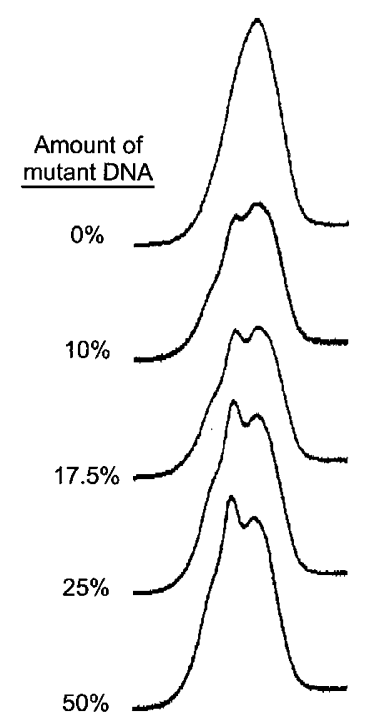

b

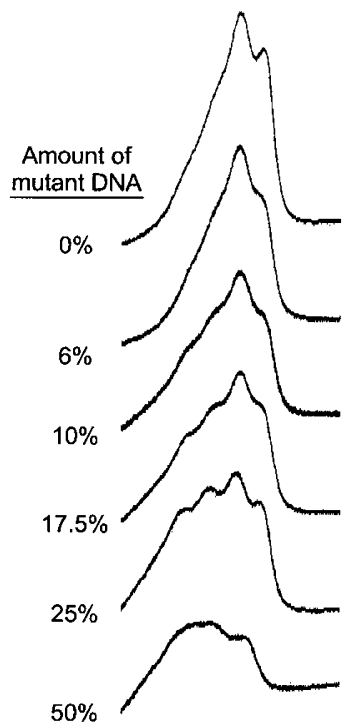

Fig. 2 DHPLC mutation detection following dilution of heterozygous mutant PCR products with wild-type PCR products. The amount of mutant DNA ranged from $0 \%$ to $50 \%$. The elution profiles shown in panels a and b were, respectively, those observed with the GJB1 mutation $43 \mathrm{delC}$ and the MPZ mutation 522-525delGCTT.

As illustrated by the elution profiles for PCR products of $M P Z$ exon 2, detection of a heteroduplex is very sensitive to the column temperature (Fig. 1a). The elution profiles of both patient samples could be distinguished readily from the control sample at $61^{\circ} \mathrm{C}$, but one or the other of the two patient profiles was minimally different from the control at $60^{\circ} \mathrm{C}$ or $62^{\circ} \mathrm{C}$. The alterations in the DHPLC elution profile observed with these two patients were typical for most mutations, although a few mutations gave greater separation of the heteroduplex and homoduplex peaks (Fig. 1b). Resolution as robust as that shown in Figure $1 \mathrm{~b}$ occurred only approximately $20 \%$ to $30 \%$ of the time. The most common change we observed in the elution profiles was an alteration of the time of elution.

Since DHPLC depends on the detection of heteroduplexes, this method requires the addition of an unrelated patient sample or control DNA to detect homozygous or hemizygous mutations. Appropriate pooling of patient samples could also increase the efficiency of DHPLC. To determine the sensitivity of DHPLC for detecting mutations, we mixed varying proportions of wild-type and mutant DNA from two amplicons: $M P Z$ exon 4 and GJB1 exon 2. We found that we could detect as little as $10 \%$ mutant product in a sample and that there was little difference in the elution profiles of samples with $50 \%$ or $25 \%$ mutant product (Fig. 2). We also found that we could detect mutations in a mixture of DNA from three patients who each had a different mutation in the amplicon (data not shown). Therefore, pooling the amplicons from two unrelated patients may be an efficient and sensitive method for DHPLC mutation screening.

\section{Comparison of DHPLC with direct sequencing for mutation detection}

Using DHPLC to screen for heteroduplexes in PCR amplicons containing the coding regions and associated exon-intron boundaries of $M P Z, P M P 22, G J B 1$, and EGR2, we identified 24 elution profiles suggestive of a heteroduplex in a cohort of 168 CMT patients that had previously tested negative for diseasecausing mutations in these amplicons by direct sequencing. For 12 of the 24 samples, we were unable to identify the sequence variation that produced the altered elution profile. Ten of the 24 positive samples contained sequence variants that either were in the intron or did not alter the predicted amino acid. However, two samples contained mutations that would be predicted to alter the coding sequence of GJB1. Analysis of the sequence chromatograms from these two samples revealed that on both the sense and antisense sequence, the intensity of the peak for the mutant nucleotide was too low for the sequence analysis program to detect the ambiguity (Fig. 3a and c). We confirmed both mutations by restriction endonuclease digestion (Fig. $3 b$ and $d$ ). Our results revealed that sequence of both sense and antisense strands is insufficient for detection of all mutations when using sequencing analysis programs to identify ambiguous bases.

\section{DISCUSSION}

Although DNA sequence analysis has been considered the gold standard for mutation detection, we have shown that this method was not completely sensitive when sequence analysis programs were used to identify heterozygous mutations. In contrast, DHPLC was capable of detecting all mutations identified by sequencing as well as additional mutations. Reports for DHPLC mutation detection in other diseases have also shown sensitivities of $92.5 \%$ to $100 \% .{ }^{11,14-19}$ Lacking a standard by which to define a set of DNA samples without sequence variations, we are unable to determine a definite falsepositive rate for DHPLC. Because half of our samples with a DHPLC elution profile suggestive of a heteroduplex did not have a mutation which could be detected by automated sequencing, the false-positive rate of DHPLC analysis could be as high as $50 \%$; however, the absence of an identifiable sequence alteration could also be secondary to the lower sensitivity of DNA sequencing and might suggest that the sensitivity of DNA sequencing could be increased by sequencing the DNA in the heteroduplex fraction collected from the DHPLC column. Our results suggest that when optimized for known mutations, DHPLC may perform better than conventional automated DNA sequence analysis for patient mutation detection.

In addition to improving the sensitivity of mutation detection, DHPLC also reduces cost and improves efficiency. In our experience, analysis of DHPLC profiles is 10-fold faster than sequence analysis, and the reagent costs for DHPLC are at least 5-fold less. Using ABI reagents and an ABI 377 automated sequencer, the reagent and maintenance cost for DNA sequencing is approximately $\$ 5$ to $\$ 7$ dollars per sample, whereas 
a

Patient 4
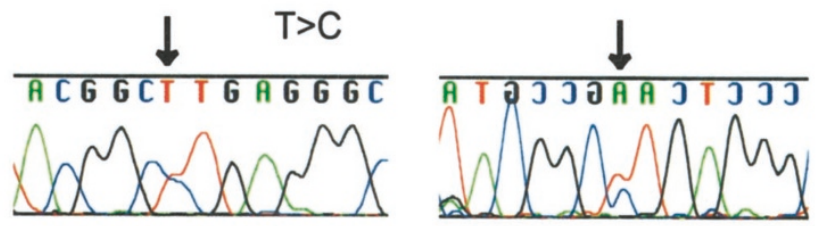

ACGGCTTGAGGGC

Wild type
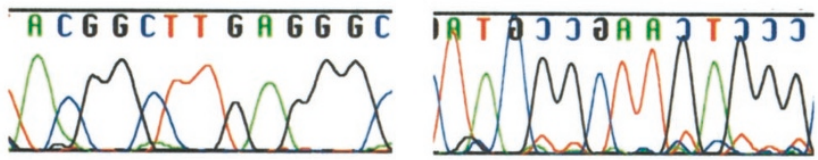

b Bsu36l digestion

$$
5^{\prime} \ldots \text {...CC/TNAGG...3' }
$$

Mutation ...CC/TGAGG...
Wild type ...CTTGAGG...

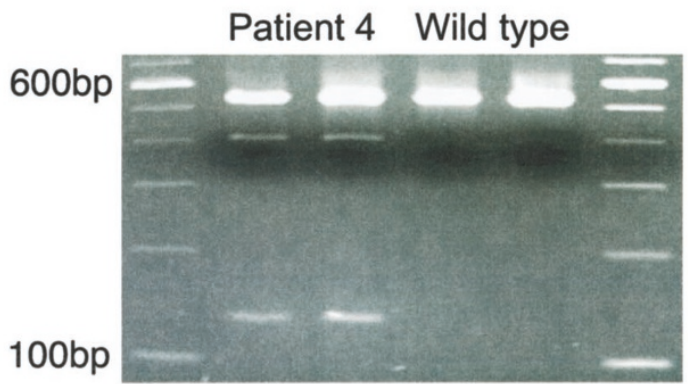

C
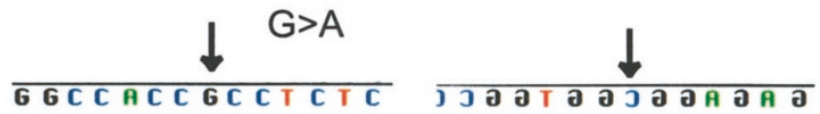

Patient 5
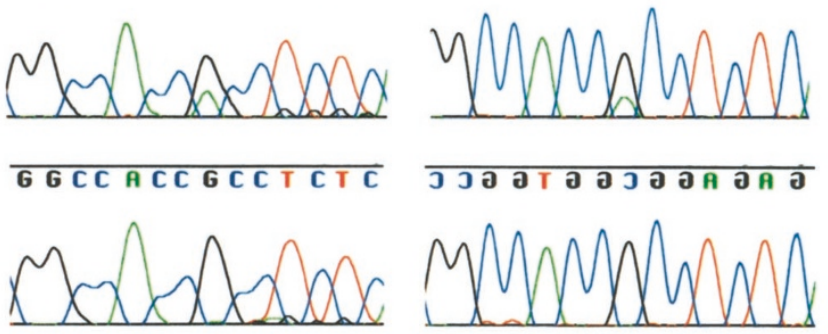

Wild type

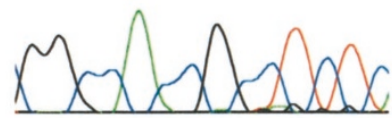

d Aci I digestion

$$
5^{\prime} \ldots \text {..C/CGC ....3' }
$$

Wild type ..AC/CGCC... Mutation ..ACCACC...
Patient 5 Wild type Cut Uncut Cut Uncut

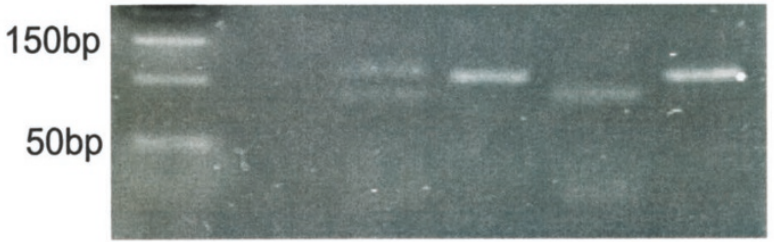

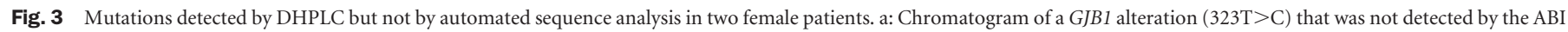

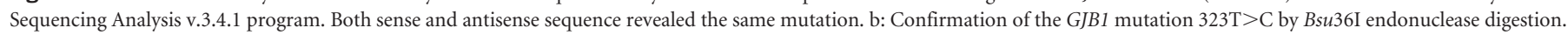

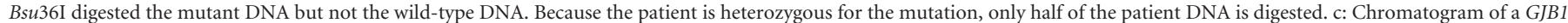

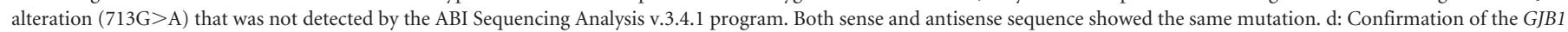

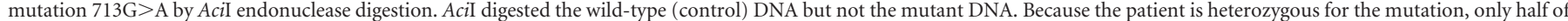

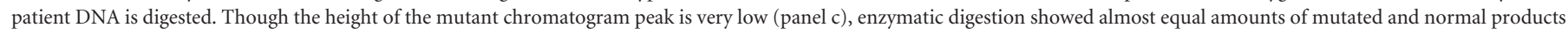
in patient 5 .

DHPLC costs approximately $\$ 0.9$ per sample using the Transgenomic WAVE system. Approximate per sample costs for DNA sequencing are: $\$ 5.50$ for forward and reverse dye primer sequencing reagent, $\$ 0.25$ for ABI377 maintenance, and $\$ 1.25$ for optional purification of the PCR product prior to sequencing. The approximate per sample costs for DHPLC analysis are 
$\$ 0.40$ for DHPLC buffers, $\$ 0.40$ for the DHPLC column, and $\$ 0.10$ for equipment maintenance. Additionally, the efficiency of DHPLC can be further increased by pooling patient samples without decreasing the sensitivity of mutation detection.

As with most mutation detection methods, maintaining a high degree of sensitivity and specificity with DHPLC requires optimized conditions. Elution profile differences occur secondary to alterations in oven temperature, variations in the amount of PCR product, changes in the condition of the DHPLC buffer and the quality of instrument maintenance. Therefore, since a heteroduplex frequently has only subtle effects on the elution profile, slight differences in the experimental conditions can produce false-negative and false-positive test results. Optimization also requires the mixing of at least two patient samples or a patient sample and control DNA to detect homozygous mutations and overlapping adjacent PCR amplicons beyond the primer sequences because, in our experience, mutations within the sequences homologous to the primer do not form stable heteroduplexes and, thus, are difficult, if not impossible, to detect.

In conclusion, we established that DHPLC is a highly sensitive screening method for mutation detection in CMT and that it can increase the sensitivity of sequencing and focus sequencing on those amplicons from patient samples with sequence alterations. The incorporation of DHPLC mutation screening into protocols for mutation identification in genetically heterogeneous disorders may greatly improve the efficiency and decrease the cost of such testing.

\section{Note Added in Proof}

Consistent with our hypothesis that analysis of DHPLC heteroduplex fractions would further increase the sensitivity of DNA sequencing, we have identified mutations in limited number of PCR amplicons that had a DHPLC heteroduplex elution profile but no identifiable mutation by ABI dye-primer DNA sequencing of the original PCR product. However, enrichment for the mutant DNA by collection of DHPLC heteroduplex fractions allowed detection of the mutant bases using ABI dye-primer DNA sequencing.

\section{Acknowledgments}

We thank the families described for their cooperation. We thank Dr. C. Van Broeckhoven, Dr. P. De Jonghe, and Dr. V. Timmerman at University of Antwerp, Antwerpen, Belgium, for supplying some control DNA samples. H.T. is a recipient of a postdoctoral fellowship from the Charcot-Marie-Tooth Association. This study was supported in part by grants from the National Institute of Diabetes, Digestive, and Kidney Diseases, $\mathrm{NIH}$ (K08 DK02738 to C.F.B), and from the National Institute of Neurological Disorders and Stroke, NIH (R01 NS27042), and the Muscular Dystrophy Association (to J.R.L.).

\section{References}

1. Robertson ND, Morton CC. Beginning of a molecular era in hearing and deafness. Clin Genet 1999;55:149-159.

2. Van Camp G, Willems PJ, Smith RJH. Nonsyndromic hearing impairment: unparalleled heterogeneity. Am J Hum Genet 1997;60:758-764.

3. Willems PJ. Genetic causes of hearing loss. N Engl J Med 2000;342:1101-1109.

4. Dryja TP, Li T. Molecular genetics of retinitis pigmentosa. Hum Mol Genet 1995;4: 1739-1743.

5. Inglehearn CF. Molecular genetics of human retinal dystrophies. Eye 1998;12:571579.

6. Gu S, Kumaramanickavel G, Srikumari CR, Denton MJ, Gal A. Autosomal recessive retinitis pigmentosa locus RP28 maps between D2S1337 and D2S286 on chromosome 2p11-p15 in an Indian family. J Med Genet 1999;36:705-707.

7. Lupski JR, Garcia CA. Charcot-Marie-Tooth peripheral neuropathies and related disorders. In: Scriver CR, Beaudet AL, Sly WS, Valle D, editors. The metabolic and molecular bases of inherited disease, 8th Ed. New York: McGraw-Hill, 2001:5759_ 5788.

8. Boerkoel CF, Lupski. JR. Hereditary motor and sensory neuropathies. In: Rimoin DL, Pyeritzt R, Korf B, Connor M, editors. Emery and Rimoin's Principles and Practice of Medical Genetics, 4th Ed. London: Harcourt, 2001:53-70.

9. Boerkoel CF, Takashima H, Stankiewicz P, Garcia CA, Leber SM, Rhee-Morris L, Lupski JR. Periaxin mutations cause recessive Dejerine-Sottas neuropathy. Am J Hum Genet 2001;68:325-333.

10. Bomont P, Cavalier L, Blondeau F, Ben Hamida C, Belal S, Tazir M, Demir E, Topaloglu H, Korinthenberg R, Tysz B, Landrieu P, Hentati F, Koenig M. The gene encoding gigaxonin, a new member of the cytoskeletal BTB/kelch repeat family, is mutated in giant axonal neuropathy. Nat Genet 2000;26:370-374.

11. Choy YS, Dabora SL, Hall F, Ramesh V, Niida Y, Franz D, Kasprzyk-Obara J, Reeve MP, Kwiatkowski DJ. Superiority of denaturing high performance liquid chromatography over single-stranded conformation and conformation-sensitive gel electrophoresis for mutation detection in TSC2. Ann Hum Genet 1999;63:383-391.

12. Cotton RGH. Current methods of mutation detection. Mutat Res 1993;285:125144.

13. Oefner PJ, Underhill PA. Comparative DNA sequencing by denaturing high-performance liquid chromatography (DHPLC). Am J Hum Genet 1995;57(Suppl):A266.

14. Oefner PJ, Underhill PA. DNA mutation detection using denaturing high-performance liquid chromatography (DHPLC). In: Dracopoli NC, Haines JL, Korf BR, Moir DT, Morton CC, Seidman CE, Seidman JG, Smith DR, editors. Current protocols in hum genet. New York: Wiley \& Sons, Supplement, 1998;19:7.10.1-7.10.12.

15. O'Donovan MC, Oefner PJ, Roberts SC, Austin J, Hoogendoorn B, Guy C, Speight G, Upadhyaya M, Sommer SS, McGuffin P. Blind analysis of denaturing high-performance liquid chromatography as a tool for mutation detection. Genomics 1998; 52:44-49.

16. Gross E, Arnold N, Goette J, Schwarz-Boeger U, Kiechle M. A comparison of BRCA1 mutation analysis by direct sequencing, SSCP and DHPLC. Hum Genet 1999;105: 72-78.

17. Wagner T, Stoppa-Lyonnet D, Fleischmann E, Muhr D, Pags S, Sandberg T, Caux V, Moeslinger R, Langbauer G, Borg A, Oefner P. Denaturing high-performance liquid chromatography detects reliably BRCA1 and BRCA2 mutations. Genomics 1999;62:369-376.

18. Buyse IM, Fang P, Hoon KT, Amir RE, Zoghbi HY, Roa BB. Diagnostic testing for Rett syndrome by DHPLC and direct sequencing analysis of the MECP2 gene: identification of several novel mutations and polymorphisms. Am J Hum Genet 2000;67: $1428-1436$.

19. Liu W, Smith DI, Rechtzigel KJ, Thibodeau SN, James CD. Denaturing high performance liquid chromatography (DHPLC) used in the detection of germline and somatic mutations. Nucleic Acids Res 1998;26:1396-1400.

20. den Dunnen JT, Antonarakis SE. Mutation nomenclature extensions and suggestions to describe complex mutations: a discussion. Hum Mutat 2000;15:7-12. 